\title{
Avant- propos. Le massif forestier, espace géographique et territoire
}

Jean-Pierre Husson et Xavier Rochel

\section{OpenEdition}

\section{Journals}

Édition électronique

URL : http://journals.openedition.org/rge/1914

DOI : $10.4000 /$ rge. 1914

ISSN : 2108-6478

Éditeur

Association des géographes de l'Est

Édition imprimée

Date de publication : 1 janvier 2009

ISSN : 0035-3213

Référence électronique

Jean-Pierre Husson et Xavier Rochel, «Avant- propos. Le massif forestier, espace géographique et territoire », Revue Géographique de l'Est [En ligne], vol. 49 / 2-3 | 2009, mis en ligne le 06 octobre 2010, consulté le 08 septembre 2020. URL : http://journals.openedition.org/rge/1914 ; DOI : https://doi.org/ $10.4000 /$ rge. 1914

Ce document a été généré automatiquement le 8 septembre 2020

Tous droits réservés 


\title{
Avant- propos. Le massif forestier, espace géographique et territoire
}

\author{
Jean-Pierre Husson et Xavier Rochel
}

1 Le massif forestier s'entend comme un ensemble foncier (une forêt domaniale, communale, sectionale ou privée) ou, dans une acception probablement plus pertinente en géographie, comme un ensemble boisé distinct, plus ou moins homogène, à l'échelle paysagère ou régionale. Le massif est un bel objet géographique dans la mesure où il forme une unité spatiale pertinente pour aborder la forêt dans sa dimension multifonctionnelle, ou encore comme lieu porteur de synergies internes. Trop longtemps considéré comme une marge, voire une coupure subie ou entretenue, le massif représente la bonne échelle pour établir des projets cohérents, associer une approche écosystémique, cynégétique, ou encore récréative à la production, pour mettre en scène et afficher le paysage forestier, en particulier si celui-ci s'inscrit dans un contexte urbain ou une forte exposition au regard.

2 Ce numéro thématique réunit sept articles, avec majoritairement de jeunes chercheurs et le souci d'énoncer de la transdisciplinarité, avec trois forestiers, deux écologues et une archéologue. Bref, ce numéro se veut résolument passeur de frontières, rassembleur sur un objet qui fut longtemps inscrit en position de diffluence. Il est accompagné de plusieurs présentations d'ouvrages en liaison avec le thème central.

3 L'idée transversale qui parcourt ce numéro est que le massif est devenu un territoire à part entière, avec un projet d'aménagement prudent réalisé dans un souci de transmission de la ressource sur pied mais également du patrimoine. Robin Degron et Benoît Boutefeu, qui sont à la fois forestiers et géographes, énoncent parfaitement la problématique du numéro en apportant, à deux échelles complémentaires, une approche novatrice du massif. Il s'agit d'un territoire ouvert au fait régional et où débute la pratique d'une gouvernance sylvicole souvent récente, après deux siècles au moins de domination technicienne du forestier sur son domaine. Ce changement invite à la mise en scène du massif, autrement dit à revoir sa gestion en tenant compte de sa perception et de ses représentations, en conciliant écologie du paysage et images de territoire. 
Suite à ce préalable, le massif est reconsidéré dans un contexte géographique et historique élargi. Marc Galochet l'observe dans ses deux principales dimensions, territoriale et qualitative, et dans le cadre de ses marges, avec un double regard porté du dedans et du dehors afin de montrer toutes les connivences qui relient le bois et son environnement agricole. Ce regard s'inscrit dans le contexte biogéographique d'une forêt fragmentée, réduite à des isolats ou « îlots » au sein des espaces ouverts. Xavier Rochel inverse ce regard dans son analyse des premiers procès-verbaux d'aménagement du XIXe siècle, où il se penche sur les trouées qui percent, ou perçaient autrefois les massifs forestiers, formant en quelque sorte des îlots ouverts dans une matrice fermée. En associant les pratiques et les outils de la biogéographie et de la géographie historique, avec pour objet d'étude les forêts domaniales vosgiennes, il invite à revisiter le massif avec un regard diachronique, conscient d'un passé qui a pu durablement marquer l'écosystème forestier.

Cette préoccupation est reprise dans la communication de Murielle Georges-Leroy, archéologue, Jérôme Bock, forestier, Etienne Dambrine et Jean-Luc Dupouey, de l'INRA. Avec leurs partenaires, ils ont mené ces dernières années un travail tout à fait exceptionnel d'exhumation de la mémoire des sols du massif de Haye, balayé par une mission LIDAR. Celle-ci a permis d'identifier et cartographier des finages créés à la fin de la paix romaine sur des sols minces, pauvres mais faciles à travailler et placés en position défensive ; un exemple qui montre très clairement la mobilité des massifs dès que l'on se place sur des temps longs, ronds mais également rompus, cassés. L'opposition classique entre «vieilles forêts » et «nouvelles forêts " (Paul Arnould) peut et doit être considérée à plusieurs échelles de temps.

Claire Labrue restitue ensuite quelques uns des résultats de sa thèse pour laquelle elle a exploré les notions d'enfermement et de fermeture des paysages, répondant ainsi à un enjeu de société tout à fait considérable, voire primordial dans les régions françaises les plus boisées. Elle présente ici une étude de cas sur les Vosges gréseuses, où s'observent des configurations paysagères devenues oppressantes pour les populations vivant sur place.

7 Enfin, Jean-Pierre Husson s'attache également aux enjeux d'actualité en revisitant le massif de Haye, vaste infrastructure de proximité pour l'agglomération de Nancy, apprécié pour l'aménité du cadre qu'il offre aux populations urbaines, et actuellement au début d'une procédure de classement de protection inédite à l'échelle nationale, sinon dans ses finalités, du moins dans ses modalités de mise en oeuvre.

8 Dans la diversité des points de vue évoqués et des échelles spatio-temporelles retenues, les éclairages fournis montrent la richesse des questions posées à propos du massif forestier qui prend du sens, de l'autonomie, de la reconnaissance en tant que territoire, objet d'étude et objet d'aménagement au delà du seul aspect sylvicole. 


\section{AUTEURS}

XAVIER ROCHEL

Centre d'Etudes et de Recherches sur les Paysages, Université Nancy 2 